\title{
Teknokultura
}

ISSNe: 1549-2230

http://dx.doi.org/10.5209/TEKN.55441

\section{Walking into the cyborg gym. Two conceptions of the cyborg athlete}

\author{
Francisco Javier López Frías ${ }^{1}$
}

Recibido: 10 de marzo de 2017 / Renviado para revisión: 14 de julio de 2017 / Aceptado: 14 de diciembre de 2017. Open peer reviews

\begin{abstract}
In this paper, I will draw on the different notions of the cyborg to explore the normative implications of technology use in sport. To do so, I will first analyze the colloquial notion of the cyborg (Section 1). Then, I will differentiate between transhuman cyborgs, which are enhanced human beings who keep their defining human characteristics intact from the impact of technology, from posthuman cyborgs, which are beings whose involvement with technology blurs the line between what is human and what is not (Section 2). By applying the transhuman/posthuman distinction to sport, I will differentiate transhuman sport from posthuman sport. These two notions of sport will provide the basis for analyzing two conceptions of the cyborg-athlete: the transhuman cyborg-athlete and the posthuman one (Section 3). To conclude, I will identify the transhuman cyborg-athlete as the prevailing notion of the cyborg in contemporary sports and will present the main normative challenges that each conception of the cyborg-athlete raises.
\end{abstract}

Keywords: ethics of technology; human nature; posthumanism; sport ethics; transhumanism.

\section{[es] Entrando al gimnasio de los ciborgs. Dos concepciones del ciborg atleta}

Resumen. En este artículo me basaré en las diferentes concepciones del ciborg para explorar las implicaciones normativas del uso de tecnología en el deporte. En primer lugar analizaré nuestra concepción coloquial del ciborg (Sección 1). Seguidamente distinguiré entre el ciborg transhumano, que es un ser mejorado que mantiene sus caracteres definitorios humanos a salvo del impacto de la tecnología, del ciborg posthumano, que es un ser cuya relación con la tecnología hace imposible trazar una línea entre lo que es humano y lo que no (Sección 2). Aplicando la distinción entre lo transhumano y lo posthumano, distinguiré entre deporte transhumanos y posthumanos. Estas dos nociones del deporte proporcionan la base para analizar dos concepciones del ciborg-atleta: el transhumano y el posthumano (Sección 3). Para concluir, identificaré el ciborg-atleta transhumano como la noción dominante en el deporte actual y presentaré los principales retos legales que surgen en relación a cada concepción del ciborg-atleta.

Palabras clave: ética del deporte; ética de la tecnología; naturaleza humana; posthumanismo; transhumanismo.

Summary: 1. Introduction. 2. The concept of "cyborg." 3. Transhuman and posthuman cyborgs. 4. Transhuman and posthuman sport.

Cómo citar: López Frías, F.J. "Walking into the cyborg gym. Two conceptions of the cyborg athlete": Teknokultura, vol. 15 (1) 2018, pp. 105-117.

1 The Pennsylvania State University, Kinesiology Department and Rock Ethics Institute (United States)

Email: fj113@psu.edu 


\section{Walking into the Cyborg Gym? Who would we find?}

The concept "cyborg" is prevalent in contemporary social and philosophical thinking, particularly in the disciplines of gender studies, epistemology, technology studies, sport ethics, and posthumanism ${ }^{2}$. To investigate the concept, Mentor, in "The Coming of the Mundane Cyborg," invites us to imagine a business that only accepts cyborgs as members (Mentor, 2011, p. 48). Given the sporting theme of this paper, let us suppose that such a business was a cyborg gym. What kind of people should we expect to find if we walked into it?

According to Mentor (2011), most people would expect to find half-human, half-robot beings like Wolverine, RoboCop, the Bionic Woman, Iron Man, and Inspector Gadget. This expectation would go in line with the colloquial understanding of the cyborg as "a person whose physical abilities are extended beyond normal human limitations by mechanical elements built into the body" (Oxford Dictionary). However, Mentor (2011) thinks otherwise. For him, the cyborgs mentioned above do not exhaust the meaning of the concept. They might be "VIP members" of the gym, but there is another type of cyborg that we must consider as a legitimate member, namely the "mundane cyborg" (Mentor, 2011).

By "mundane cyborgs," Mentor means human beings who rely on technology to solve problems (Mentor, 2011, p. 49). Examples of mundane cyborgs are Oscar Pistorius running on the treadmill on his carbon legs and teenagers using their smartphones to monitor their exercise. Thus, according to Mentor's mental experiment, the cyborg gym should drop "its fiber-optic velvet rope" and "say hello to the Mundane Cyborg" (Mentor, 2011, p. 49). According to Gray, Mentor and Figueroa-Sarriera (2011, pp. 2-3):

Even if many individuals in the industrial and post-industrial countries aren't full cyborgs, we certainly all live in a "cyborg society." Machines are intimately interfaced with humans on almost every level of existence [...] There are many actual cyborgs among us in society. Anyone with an artificial organ, limb or supplement (like a pacemaker), anyone reprogrammed to resist disease (immunized) or drugged to think/behave/feel better (psychopharmacology) is technically a cyborg [...] It's not just Robocop, it is our grandmother with a pacemaker.

Gray, Mentor, and Figueroa-Sarriera's claim echoes that of Haraway in an interview with Kunzru (2006):

Winning the Olympics in the cyborg era isn't just about winning fast. It's about 'the interaction of machine, diet, training practices, clothing, and equipment manufacture, visualization and timekeeping. (Haraway in Geertsema, 2006, p. 295)

Drawing on Haraway (1995), Butryn (2002), Ryall (2012), and Miah (2003) popularized the use of the term "cyborg" in the arena of the philosophy of sport

2 Indeed, the popularity of the term has given rise to a new academic discipline, namely cyborg anthropology, which, according to Donna Haraway, "forces [us] to pay attention to kinship. Who are my kin[,] who are my familiars, my siblings, and what kind of livable world are we trying to build?". (Haraway, 1997, p. 52 in Nayar, 2013) 
by arguing that current athletes are already cyborgs. The idea of the cyborg-athlete raises controversy and anxiety. The following Michael Sandel's thought experiment involving a bionic baseball player illustrates the anxiety cyborgs raise in the sport world: "We might imagine a robotic, bionic athlete who, thanks to implanted computer chips that perfect the angle and timing of his swing, hits every pitch in the strike zone for a home run" (Sandel, 2007, p. 26). According to Sandel, a bionic, cyborgized baseball player would remove the human element from sport performance. The elimination of such an element would corrupt the main goal to which the sport practice is intended, namely showcasing and celebrating the exercise of human physical capacities. Sandel's case against the use of performance-enhancing technologies in sport portrays bionic (cyborg) technology as disruptive and morally troublesome:

The bionic athlete would not be an agent at all; "his" achievements would be those of his inventor. According to this view, enhancement threatens our humanity by eroding human agency. Its ultimate expression is a wholly mechanistic understanding of human action at odds with human freedom and moral responsibility. (Sandel, 2007, p. 26)

In line with Sandel's concern about the participation of cyborgs in sport, Butryn argues, "We must first determine who or what is actually crossing the finish line before attempting to determine which technologically-enhanced performances will count as meaningful" (Butryn, 2002, p. 117). In addition, Schantz (2016, p. 852) says:

Cyborg athletes may prove to be so fantastic that the rest of the sporting community will no longer be able to identify with [them.] One important reason to admire and to adhere to sports is the shared human experience. We want 'to see human athletes producing performances relevant to human audiences' (Agar, 2010) and not performances of post-human competitors.

As Schantz's citation makes clear, cyborgs raise discomfort among the sport community. They threaten the celebration of human's physical gifts or natural physical capacities that is at the heart of sport. Cyborg-athletes are thought to have the potential to undermine the human elements of sport, which are regarded as the main source of value of the sport practice (López Frías, 2015). However, according to those who, like Mentor, argue that we all are already cyborgs, fear and anxiety towards the participation of cyborgs are unfounded, at least in most cases of cyborg-technology use. In this paper, to clarify the concept "cyborg-athlete," I will identify and analyze two notions of the cyborg, namely the transhuman and the posthuman. To conclude, I will explore what kind of normative implications result from each of the notions.

\section{The cyborg, origins of the concept}

In this section, I will draw on Wolfe's (2011) distinction between posthumanism and transhumanism to identify two notions of the cyborg: the transhuman cyborg and the posthuman cyborg. Transhumanism has its roots in the Renaissance humanistic 
movement, whose main tenet is the promotion of human flourishing through the development of human beings' unique characteristics, i.e., rationality, artistic skills, and technological expertise. Humanists hope that the exercise of such capabilities will lead humanity into a state of emancipation and freedom where humans achieve happiness. From this perspective, as the exercise of their most defining capacities enables humans to be happy, their animality must be suppressed or, at least, minimized to allow them to reach their full potential.

As heirs of humanism, transhumanists hold that humans' full potential "is achieved by scaping or repressing not just its animal origins in nature, the biological, and the evolutionary, but more generally by transcending the bonds of materiality and embodiment altogether" (Wolfe, 2011, p. xv). Thus, transhuman cyborgs are disembodied and fully autonomous beings who rely on technology to fully exercise their human capabilities. Nathan S. Kline and Manfred E. Clynes' notion of the cyborg best illustrates the transhuman account of the cyborg.

In contrast, posthumanism draws on the Foucauldian claim: "[M] an is an invention of recent date. And one perhaps nearing its end" (Foucault in Wolfe, 2011, p. xii). From a posthuman standpoint, there is no human essence or unique human capabilities. The concept "human" has lost its ontological, fixed status, becoming a blurred entity due to its being intertwined with different networks and systems such as technology and society. Technology permeates most human actions, if not all. It is difficult to tell where the human ends and technology begins. This is best illustrated by the cyborg, which, according to posthumanists, is the hybrid being par excellence. The concept of "cyborg" does not designate particular individuals with a technologically enhanced nature, as it does for transhumanists. Rather, it becomes a metaphor for twenty-first-century human existence.

\subsection{Transhumanist view of the cyborg}

In 1960, Kline and Clynes coined the concept of "cyborg" as a combination of the terms "cybernetic" and "organism" (citado por Madrigal, 2010). Kline and Clynes' concept emerged in the context of biomedical research on the possibility of enabling humans to live in the outer space (Clynes and Kline, 1960; Kline, 2009). They thought that human life in environments radically different from those found on Earth would only be possible by radically altering the human body. However, the radical modification that Kline and Clynes propose is not as radical as it sounds. The cyborg technology that they envisage radically modifies the body but keeps the mind intact. In this sense, their view of the cyborg is an heir of humanism and an illustration of transhumanism; what matters for them is the deployment of technology to protect and develop of what makes human beings unique, namely the rational mind.

The main goal of Kline and Clynes' cyborg technology is to free human beings from the constraints of their physical environment. Such a liberation enables enhanced humans to maximize the exercise of their human capacities by detaching them from the needs and necessities the environment imposes on them. Kline and Clynes' view of the cyborg presupposes a dualist view of human nature that regards humans' organic (material) nature as expendable. From this perspective, human nature is composed of two substances, body and mind. On the one hand, humans have a body that ties them to the physical world. On the other hand, humans have an immaterial mind that provides them with unique human capacities. According to 
(Clynes and Gray, 1995, p. 49), the use of cyborg technology would only modify the physical and animal aspects of human nature. Such technology would not lead to the transformation of human beings into a different type of being. Rather, it would leave humans" "essential identity" intact, allowing them to develop their full human potential.

The transhumanist movement, also called "Humanity+," builds upon the idea that the creation of better things, including better bodies, leads to better lives. For instance, one of its main proponents, James Hughes argues for the creation of cyborg citizens,

to reach intellectual heights as far above any current human genius as humans are above other primates; to be resistant to disease and impervious to aging; to have unlimited youth and vigor; to exercise control over their own desires, moods, and mental states; to be able to avoid feeling tired, hateful, or irritated about petty things; to have an increased capacity for pleasure, love, artistic appreciation, or serenity; to experience novel states of consciousness that current human brains cannot access. (Hughes, 2004, p. 98)

The figure of the cyborg illustrates transhumanists' fascination with the power of technology, as well as their attempt to solve humanity's problems through technology. From a transhumanist perspective, turning humans into cyborgs would be the best way to respond to the challenges that threaten their existence and hinder their possibilities to lead better lives. Among such challenges are global warming, degenerative diseases, preventing war, and hostility among cultures (Martin, 2007). The utilization of technology to solve humans' problems and better the world, according to transhumanists, is nothing new under the sun. Rather, it is inscribed in human beings' nature; it is the result of the use of reason to understand the world and bend it to humans' needs.

\subsection{A posthuman notion of the cyborg}

The transhumanist view of the cyborg heavily contrasts with the posthuman one. For most cyborg theorists, the cyborg is a "revolutionary" figure (Haraway, 2013, p. 151), not one that conserves human beings' defining elements. In "Cyborg Manifesto," Haraway attaches a revolutionary dimension to the cyborg and regards it as:

A cybernetic organism, a hybrid of machine and organism, a creature of social reality as well as a creature of fiction [that has] 'technodigested' [...] the dichotomies between mind and body, animal and human, organism and machine, public and private, nature and culture, men and women, primitive and civilized. (Haraway, 2013, p. 163)

Haraway's cyborg represents a new human ontology. One where the different humanly-created dimensions, such as the technological, the economic, the textual, and the political, are intimately intertwined, making impossible to tell where the human 
ends and those dimensions begin (Gray, Mentor and Figueroa-Sarriera, 1995, p. 13). All boundaries that define human nature are blurred nowadays. When regarded as cyborgs, human beings are beings of infection, information, intercourse, and transgression (Malatino, 2017). The cyborg, according to Haraway, has rendered other views of human nature obsolete. Humans cannot be referred to as "homo sapiens," "homo faber," or "homo ludens" anymore. These definitions, paraphrasing Haraway, "have been technodigested" by the cyborg. For instance, humans do not use tools anymore; they are not in partnership with their artificial creations but rather in symbiosis with them.

In contrast to Kline and Clynes' contention that cyborg technologies do not alter essential human aspects, from a posthumanist perspective, the symbiotic relationship between human beings and technology modifies human identity profoundly, marking a new era in human history. Humans in the past were able to use technology, but they were not in a symbiotic relationship with it. The human-technology symbiosis is the result of a specific historical process, namely the mechanization of human life and the vitalization of the machine:

By the end of World War II it was very clear that the mechanization of the human, the vitalization of the machine, and the integration of both into cybernetics was producing a whole new range of informational disciplines, fantasies, and practices that transgressed the machine-organic border. (Gray et al., 1995, p. 5)

The end of the WWII marks the beginning of the transition from an industrial society into a cybernetic one. As Thomas notes, Wiener $(1961,1964)$ identifies four leading metaphors that have provided the interpretative key to experiencing the world in the different stages of human history: the mythic Golemic age, the age of clocks, the age of steam, and the age of cybernetics or communication and control. The defining character of the cybernetic era, the current era, is that technological development has reached a point where machines have become either a plausible alternative to or an essential component of humans. Human beings view and understand the world through the metaphorical value given to the computer, that is, through computational and digital concepts and concepts. The cyborg is one such concept. In the era of cybernetics, we all have become cyborgs (Gray et al., 1995).

\section{Transhuman and posthuman cyborg-athletes}

By drawing on the distinction between transhumanism and posthumanism presented above, I will identify two accounts of sport. On the one hand, from a transhumanist perspective, sport is a quest for outstanding performances through the exercise of natural physical capacities. According to this account, technology use should be allowed when it enables human beings to push their physical limitations further without removing the human component in sport performance. In this sense, technology has a place in transhuman sports but only if it enhances the typical-human physical capacities at the core of a given sport without threatening the sport's essential elements. On the other hand, posthuman views of sport take human performance to be indistinguishable from technological use. In modern sports, technology use is so prevalent that it is impossible to differentiate what results from human capacities 
from what results from technology use. In this account of sport, it becomes impossible to draw a line between technology and human nature. The two views of sport lead to two different conceptions of the cyborg-athlete, namely the transhuman cyborg-athlete and the posthuman cyborg-athlete.

\subsection{Transhuman cyborg-athletes in sport}

The transhuman conception of the cyborg-athlete draws on a "dualist" view of athletic performance. From this perspective, human performance is the result of two distinct elements: natural human capacities and artificial tools. Technology is placed at the service of the development of the human component of sport performance. Technology is secondary, what matters is the athlete's natural capacities. Indeed, the latter become the normative criterion to adjudicate when the use of technology corrupts the nature of the practice.

Sport organizations hold a transhumanist view of sport. They establish sport competitions for humans to reach their highest level of performance possible. In these competitions, the use of technology is allowed. Indeed, the very practice of sport could be regarded as a "social technology" (Dyreson, 1998). Moreover, in most sports, technological artifacts are required to achieve the goal of the game, i.e., cycling and pole vault. However, sport organizations raise concerns when technology corrupts the natural aspects of sport. For instance, in 1996, the Union Cycliste Internationale (UCI) released the Lugano Charter to tackle ethical problems related to the implementation of sport technologies in cycling. In the Charter, UCI's main goal is to "return the sport to the cyclists," or better said, to the participants who remain "pure" or "natural" by rejecting the use of technological:

The bicycle is losing its "user-friendliness" and distancing itself from a reality which can be grasped and understood. Priority is increasingly given to form. The performance achieved depends more on the form of the man-machine ensemble than the physical qualities of the rider, and this goes against the very meaning of cycle sport. (Union Cycliste Internationale, 1996)

For the UCI, cycling should be about the physical qualities of cyclists; anything that diminishes the relevance of the cyclists' embodied capabilities is detrimental to the sport. Thus, as Tara Magdalinski points out, transhumanists face the challenge of finding a balance between two opposing elements: the appearance of naturalness and the maximization of their performance. According to Luke (1996), this challenge is not unique to sports. According to him, there is a tension between the cyborg metaphor and the principles at the core of most human societies:

[T] he more inclined we are to see our personal and collective desires through the [cyborg] images and vocabularies [...], such as "upgrades", "enhancements", and "opportunism", the less inclined we may be to question the adequacy of those very images and vocabularies as signifiers of human potential, human solidarity, 
and human flourishing, let alone as an adequate representation of "human nature". (Selinger and Engström, 2008, p. 338)

The tension between the natural and artificial components of sport performance is also found in the Olympic Movement. Although the Olympic motto is "faster, higher, and stronger" (citius, altius, fortius), the normative and eligibility criteria of Olympism draw heavily on the notion of naturalness. For instance, the World Anti-Doping Agency (WADA) states the following in the Anti-Doping Code:

Anti-doping programs seek to preserve what is intrinsically valuable about sport. This intrinsic value is often referred to as 'the spirit of sport'; it is the essence of Olympism; it is how we play true. The spirit of sport is the celebration of the human spirit, body and mind. (WADA, 2015, p. 14)

According to Magdalinski (2009), the presence of both naturalness and artificiality within sport creates a paradoxical situation. Athletes are asked to protect the naturalness of their performance, while, at the same time, being forced to rely on technology to enhance their performance. Gold medalists are not expected to be different from the other humans. Rather, they are expected to be the best individuals among them. According to Agar (2010), a typical-human sport performance is valuable, among other things, because other human beings can identify and "veridically engage" with it. Athletic performances resulting from the exclusive use of a technology to which other people have no access lack intrinsic value. To support this claim, Agar points out that humans commonly prefer excellent human performances over objectively superior performances of technologically enhanced beings or artifacts. For example, sport fans value Gebrselassie's marathon over the one of a robot who might be able to run the marathon as fast as Gebreselassie (Agar, 2014, p. 3 ) $^{3}$. People's negative reaction against enhanced athletes is present in Håkan Nyberg's question: "Will we like watching a circus of artificial animals?" (Zorpette, 1999).

According to Norman and Moola, 2011, as athletes are expected to be "faster, higher, and stronger" by solely relying on what is "truly human" (Agar, 2010, 2014), they must struggle to incorporate technological aspects within their natural athletic performance, for instance, by hiding its artificial aspect. The use of technologies should be ancillary and easily identifiable (Magdalinski, 2009, p. 50-51). This goes in line with Kline and Clynes' contention that cyborg technology does not corrupt human nature because it does not alter human identity; it does not erode what is truly human.

From a transhuman standpoint, cyborg properties that affect the identity of sport must be controlled and, in some cases, eliminated in order to keep athletes from trespassing the boundary between a human physical aspect and a cyborg one (Norman and Moola, 2011, p. 202). Cases where the artificial elements of sport performance are visible raise anxiety. For instance, Pistorius' Cheetah legs gained many detractors

\footnotetext{
Professional baseball and track and field give us excellent illustrations of the intrinsic value attached to performances untainted by technology. People prefer Usain Bolt's performance and record over those of Ben Johnson. In the case of baseball fans, Barry Bond's home run record appears with an asterisk due to steroid use. Thus, people prefer Babe Ruth's and Hank Aaron's records over Bond's.
} 
just because of their artificial aspect. Panic against the intrusion of artificial elements in sport led commentators to argue that Pistorius was not even running. As Rayvon Fouché echoes, with regard to Oscar Pistorius' participation in the 2012 London Olympics, sport commentators claimed that "[Pistorius'] prostheses work against the belief in the primacy of the human body because these devices are not of flesh and bone" (Fouché, 2017, p. 125).

The corrupting power that people commonly attach to the cyborg-athlete is reflected by the fact that, in contemporary sports, robotic images and metaphors are frequently used to refer to enhanced beings whose participation threatens the integrity of the game. The use of technology is embraced, but only when it does not corrupt the "human identity" of sport, that is, the image of naturalness of sport performance. As long as the nature of sport remains built upon the exercise of natural capacities, it is unlikely that the sporting world would embrace "the fusion of man and machine" (Fouché, 2017, p. 126). Thus, transhumanists embrace the use of some technology in sport. To differentiate between legitimate and illegitimate technology, they raise the following normative question, when does the use of a technology remove the human element from sport?

\subsection{Posthuman cyborg-athletes and sport}

The transhuman notion of the cyborg-athlete assumes that there are natural human athletic capacities. Contemporary sports are, indeed, based on a "naturalistic" ontological view of human nature (Magdalinski, 2009, p. 206). However, from a posthuman perspective, this ontology is misguided. Magdalinski points out that the natural has long been polluted by the artificial and suggests that what has been regarded as natural athletic capacities should be called "naturalized human capacities" (Magdalinski, 2009, p. 204). Humans are always embedded within a culturally meaningful network formed of organic, technological, and cultural features. Seen from this perspective, natural human performance becomes less fixed and pure, and the distinction between its natural and artificial aspects blurs.

The blurred character of the distinction between natural and artificial aspects of sport performance is the defining mark of the posthuman notion of the cyborg-athlete. From this perspective, technologies are not necessarily inherently dehumanizing. Rather, technology is inherent to contemporary sports and, therefore, ineliminable and indistinguishable from other factors involved in sport performance. In line with this idea, Butryn advocates for a reconceptualization of elite athletes as always already-cyborgified competitors. According to him, sport performance is always "polluted" through technology use (Butryn and Masucci, 2009; Butryn, 2003). The sport abilities that athletes develop are not pure but tied to the use of sport technology. Butryn differentiates between five types of sport technologies: self-technologies, landscape technologies, implement technologies, rehabilitative technologies, and movement or evaluative technologies.

Self-technologies consist in interventions that alter the physical or psychological configuration of athletes. These technologies represent the most obvious, and for many the most disturbing, form of cyborgification. Within this category, Butryn includes performance-enhancing drugs, surgical procedures, prosthetic limbs, sport psychological interventions, and genetic engineering. Landscape technologies aim at shaping the sporting environments in which athletes compete. Implement technol- 
ogies include instruments and pieces of equipment that athletes use during the sport contest as constitutive parts of them. Rehabilitative technologies are used to counter the debilitating effects of training and competition. And movement technologies are devices aimed at helping athletes and sport experts assess the form and efficiency of the athletes' body.

The omnipresence of these technologies in sports calls into question the possibility of drawing a clear-cut line between natural aspects of performance and artificial ones. Athletic bodies are not tabulae rasae, but cyborgized bodies who are inextricably linked to the technological, non-organic other (Butryn, 2003, p. 19). Thus, it seems impossible to maintain the distinction between "natural" or "organic" capacities and technology in sport. For Butryn,

\begin{abstract}
it is safe to say that the society which cyborgs inhabit is one in which intimate organic-machine interferences exist on virtually all levels [. Thus, it] is not a matter of determining whether or not an athlete is a cyborg, for it will be argued that all elite athletes are, to varying degrees, profoundly technologized. Instead, a more relevant line of questions would be: (a) What are the particular ways of being and competing for this cyborg?, and (b) How do we determine whether the performances of this cyborg count?. (Butryn, 2002, p. 116)
\end{abstract}

Viewing athletes as cyborgs places the arguments on the use of technology in sport on a new perspective. From a posthuman viewpoint, there are no human athletes participating in today's sports. Rather, paraphrasing Haraway, athletes "are always-already technologized cyborgs" (Haraway, 2013). This renders the normative criteria used to adjudicate technology use in contemporary sport inoperable. In a cyborg era, determining which part of the athlete's performance is due to nature and which to technology is impossible. For instance, according to Kalevi Heinila (cit. in Møller, 2016), athletes do not enter the arena as individuals. Rather, they are a part of larger systems formed by teams of experts that control every aspect of their performance, including training, diet, equipment, supplements intake, and psychology, as well as on performance enhancement technologies like drugs, supplements, hypobaric chambers, and recording devices. Sport performance is the result of the interplay among athletes' efforts, their support network, and technology use. Athletes are not the sole determinant of sport performance. They all are cyborgs because they live in the postmodern era of sport, where sport has "technodigested" the boundaries between natural/human and unnatural/unhuman upon which modern sports are built. Going back to Mentor's cyborg gym thought experiment, from a posthumanist perspective, the question is not whether or not the cyborg-gym should drop "its fiber-optic velvet rope" and say hi to the cyborg. The key question is, "what should we do now that cyborgs are populating not only cyborg gyms, but also the entire sport world?"

\title{
4. Conclusion: Technology and sport in a cyborgized world
}

In this paper I have analyzed the concept of the cyborg by drawing on Wolfe's distinction between transhumanism and posthumanism. Whereas transhumanism is the heir 
of Renaissance humanism, posthumanism is the offspring of the cybernetic era after WWII. From a transhuman perspective, cyborgs are enhanced human beings who keep their defining characteristics intact from the impact of technology. In contrast, in the case of the posthuman cyborg, technology penetrates the nature of enhanced beings to the extent that it is impossible to draw a line between what is human and what is not. By applying the distinction between transhumanism and posthumanism to sport, I have differentiated transhuman sports form postmodern sport. The former embraces the use of technology by inviting athletes to become higher, faster and stronger, but tries to protect sport's typical-human element away from the corrupting influence of technology. In this sense, I have argued that transhuman sport attempts to promote the overcoming of human boundaries through the development the human elements of sport performance, namely human's physical capacities. In contrast, posthuman sport eliminates the distinction between natural and artificial aspects of sport performance by regarding sport as a hybrid product. To conclude, in light of the two different notions of sport, I have provided two notions of the cyborg-athlete: a transhuman cyborg-athlete and a posthuman one. In doing so, I have identified the transhuman cyborg-athlete as the prevailing notion of the cyborg in contemporary sports and have identified the normative challenges raised by each view of the cyborg-athlete.

\section{Acknowledgments}

I would like to thank the two anonymous reviewers and Thomas E. Rorke for their valuable comments on earlier versions of this paper.

\section{References}

Agar, N. (2010). Humanity's end why we should reject radical enhancement. Cambridge, Mass.: MIT Press.

Agar, N. (2014). Truly human enhancement : a philosophical defense of limits. Massachusetts: MIT Press.

Butryn, T. M. (2002). Cyborg horizons: Sport and the ethics of self-technologization. In A. Miah \& S. B. Eassom (Eds.), Sport technology: history, philosophy and policy (Vol. 21, pp. 111-134). Amsterdam: JAI.

Butryn, T. M. (2003). Posthuman Podiums: Cyborg Narratives of Elite Track and Field Athletes. Sociology of Sport Journal, 20(1), 17-39.

Butryn, T. M., \& Masucci, M. A. (2009). Traversing the Matrix: Cyborg Athletes, Technology, and the Environment. Journal of Sport \& Social Issues, 33(3), 285-307.

Clark, A. (2004). Natural-born Cyborgs: Minds, Technologies, and the Future of Human Intelligence. Oxford University Press.

Clynes, M. E., \& Gray, C. H. (1995). An interview with Manfred Clynes. In C. H. Gray (Ed.), The cyborg handbook (pp. 43-53). New York: Routledge.

Clynes, M. E., \& Kline, N. S. (1960). Cyborgs and Space. Astronautics, 5(9), 26-27; 74-76.

Crawford, C. S. (2015). Body Image, Prostheses, Phantom Limbs. Body \& Society, 21(2), 221-244.

Critical Art Ensemble. (1998). Flesh machine: cyborgs, designer babies, and new eugenic consciousness. Brooklyn, NY: Autonomedia. 
Dyreson, M. (1998). Making the American team: sport, culture, and the Olympic experience. Urbana: University of Illinois Press.

Dartnall, T. (2004). We Have Always Been . . Cyborgs. Metascience, 13(2), 139-181.

Foucault, M. (2010). The order of things: an archaeology of the human sciences. London: Routledge.

Fouché, R. (2017). Game changer: the technoscientific revolution in sports. Baltimore: John Hopkins University Press.

Geertsema, H. G. (2006). Cyborg: Myth or Reality? Zygon ${ }^{\circledR}, 41(2)$, 289-328.

Gray, C. H., Mentor, S., \& Figueroa-Sarriera, H. J. (1995). Cyborgology: Constructing the knowledge of cybernetic organisms. En C. H. Gray (Ed.), The cyborg handbook (pp. 1-16). New York: Routledge.

Haraway, D. (1995). Cyborgs and Symbionts: Living Together in the New World Order. In C. H. Gray (Ed.), The cyborg handbook (pp. xi-xx). New York: Routledge.

Haraway, D. (2013). Simians, Cyborgs, and Women: The Reinvention of Nature. New York: Routledge.

Hughes, J. (2004). Citizen Cyborg: why democratic societies must respond to the redesigned human of the future. Boulder, Colo.: Westview Press.

Kline, R. (2009). Where are the Cyborgs in Cybernetics? Social Studies of Science, 39(3), 331-362.

López Frías, F. J. (2015). 21st century doping: Enhancing physical performance through biotechnical means. In B. Andrieu (Ed.), Vocabulaire international de philosophie du sport. Tome 2. Les nouvelles recherches (pp. 577-603). Paris: L'Harmattan.

López Frías, F. J. (2016). The Defining Components of the Cyborg: Cyborg-Athletes, Fictional or Real? Sport, Ethics and Philosophy, 10(1), 97-111.

Luke, T. W. (1996). Liberal Society and Cyborg Subjectivity: The Politics of Environments, Bodies, and Nature. Alternatives: Global, Local, Political, 21(1), 1-30.

Mackenzie, A. (2004). Contribution to "We Have Always Been... Cyborgs," Review Symposium for Natural Born Cyborgs. Metascience, 13, 153-63.

Madrigal, A. C. (2010). The Man Who First Said «Cyborg,» 50 Years Later [online]. The Atlantic. Retrieved from: https://www.theatlantic.com/technology/archive/2010/09/the-man-who-firstsaid-cyborg-50-years-later/63821/ [2018, February 20].

Magdalinski, T. (2009). Sport, technology and the body: the nature of performance. London: Routledge.

Malatino, H. (2017). Biohacking Gender: cyborgs, coloniality, and the pharmacopornographic era. Angelaki. Journal of the Theoretical Humanities, 22, 179-190.

Martin, J. (2007). The meaning of the 21st century: a vital blueprint for ensuring our future. London: Eden Project.

McNamee, M. (2013). Transhuman Athletes and Pathological Perfectionism: Recognising Limits in Sport and Human Nature. In J. Tolleneer, S. Sterckx, \& P. Bonte (Eds.), AthleticEnhancement, Human Nature and Ethics: Threats and Opportunities of Doping Technologies (Vol. 52, pp. 185-198). Dordrecht: Springer Netherlands.

Mentor, S. (2011). The coming of the Mundane Cyborg. Teknokultura, 8(1), 47-61.

Miah, A. (2003). Be very afraid: Cyborg athletes, transhuman ideals \& posthumanity. Journal of Evolution and Technology, 13(2).

Møller, V. (2016). The road to hell is paved with good intentions-A critical evaluation of WADA's anti-doping campaign. Performance Enhancement \& Health, 4(3), 111-115.

Nayar, P. K. (2013). Posthumanism. Cambridge: Polity.

Norman, M. E., \& Moola, F. (2011). 'Bladerunner or boundary runner'?: Oscar Pistorius, cyborg transgressions and strategies of containment. Sport in Society, 14(9), 1265-1279. 
Ryall, E. (2012). Human, athletes and cyborgs: Where next for sport? Bulletin of Sport and Culture, 35, 7-9.

Sandel, M. J. (2007). The case against perfection: ethics in the age of genetic engineering. Cambridge, Mass.: Belknap Press of Harvard University Press.

Schantz, O. J. (2016). Coubertin's humanism facing post-humanism - implications for the future of the Olympic Games. Sport in Society, 19(6), 840-856.

Selinger, E., \& Engström, T. (2008). A moratorium on cyborgs: Computation, cognition, and commerce. Phenomenology and the Cognitive Sciences, 7(3), 327-341.

Thweatt-Bates, J. (2012). Cyborg selves: a theological anthropology of the posthuman. Farnham, Surrey, England; Burlington, VT: Ashgate.

Union Cycliste Internationale (1996). Lugano Charter [online]. Retrieved from: http://oldsite. uci.ch/imgarchive/Road/Equipment/The\%20Lugano\%20charter.pdf [2018, February 14].

WADA (2015). World Anti-Doping Code 2015 [online]. Retrieved from: https://wada-mainprod.s3.amazonaws.com/resources/files/wada-2015-world-anti-doping-code.pdf [2018, February 15]

Wiener, N. (1961). Cybernetics; or, Control and communication in the animal and the machine. New York: M.I.T. Press.

Wiener, N. (1964). God and Golem, inc.; a comment on certain points where cybernetics impinges on religion. Cambridge: M.I.T. Press.

Wolfe, C. (2011). What is posthumanism? Minneapolis, Minn: Univ. of Minnesota Press.

Zorpette, G. (1999). Muscular Again. Scientific American, 10(3), 27-31. 